\title{
Effect of the enucleation procedure on the reprogramming potential and developmental capacity of mouse cloned embryos treated with valproic acid
}

\author{
Nuno Costa-Borges, Sheyla Gonzalez, Josep Santaló and Elena Ibáñez \\ Departament de Biologia Cel·lular, Fisiologia i Immunologia, Facultat de Biociències, Universitat Autònoma de \\ Barcelona, 08193 Bellaterra, Barcelona, Spain \\ Correspondence should be addressed to E Ibáñez; Email: elena.ibanez@uab.cat
}

\begin{abstract}
Mouse recipient cytoplasts for somatic cell nuclear transfer (SCNT) are routinely prepared by mechanical enucleation (ME), an invasive procedure that requires expensive equipment and considerable micromanipulation skills. Alternatively, oocytes can be enucleated using chemically assisted (AE) or chemically induced (IE) enucleation methods that are technically simple. In this study, we compared the reprogramming potential and developmental capacity of cloned embryos generated by $\mathrm{ME}, \mathrm{AE}$, and IE procedures and treated with the histone deacetylase inhibitor valproic acid. A rapid and almost complete deacetylation of histone $\mathrm{H} 3 \mathrm{Hysine} \mathbf{1 4}$ in the somatic nucleus followed by an equally rapid and complete re-acetylation after activation was observed after the injection of a cumulus cell nucleus into ME and AE cytoplasts. In contrast, histone deacetylation occurred at a much lower level in IE cytoplasts. Despite these differences, the cloned embryos generated from the three types of cytoplasts developed into blastocysts of equivalent total and inner cell mass mean cell numbers, and the rates of blastocyst formation and embryonic stem cell derivation were similar among the three groups. The cloned embryos produced from ME and AE cytoplasts showed an equivalent rate of full-term development, but no offspring could be obtained from the IE group, suggesting a lower reprogramming capacity of IE cytoplasts. Our results demonstrate the usefulness of AE in mouse SCNT procedures, as an alternative to ME. AE can facilitate oocyte enucleation and avoid the need for expensive microscope optics, or for potentially damaging Hoechst staining and u.v. irradiation, normally required in ME procedures.
\end{abstract}

Reproduction (2011) $\mathbf{1 4 1} 789-800$

\section{Introduction}

Even though new methods for genomic reprogramming have been developed in the last few years (Cowan et al. 2005, Takahashi \& Yamanaka 2006, Okita et al. 2010), somatic cell nuclear transfer (SCNT) is still the only valid tool that offers the possibility to generate either embryonic stem cells (ntESCs) or a new organism from a single cell. However, although a considerable number of reconstructed oocytes can reach the blastocyst stage and give rise to $\mathrm{ntESCs}$, the generation of live offspring remains extremely inefficient, especially in mice ( $<1-2 \%$; Yang et al. 2007, Thuan et al. 2010). In addition, the few cloned mice that develop to term frequently exhibit several fetal and post-natal abnormalities, including placentomegaly (Wakayama \& Yanagimachi 1999, Tanaka et al. 2001), obesity (Tamashiro et al. 2000, 2002), or premature death (Ogonuki et al. 2002). These abnormalities have been related to the incorrect or insufficient competence of the enucleated oocytes (cytoplasts) to remove epigenetic marks of the transferred nucleus and to reprogram it correctly first into a totipotent embryonic state and later into various differentiated states during post-implantation development (Yang et al. 2007). In this sense, oocyte enucleation is a crucial step in SCNT procedures, because an excessive loss of cytoplasm with important factors involved in nuclear reprogramming or embryonic development may irremediably affect the overall success of the SCNT procedure (Fulka et al. 2004, Li et al. 2004).

Until now, mechanical enucleation (ME) of metaphase II (MII)-stage oocytes has been the most preferred method used for the preparation of the recipient cytoplasts in SCNT protocols. These cytoplasts are prepared by aspiration of the MII plate and the associated spindle with a micropipette, which is a very efficient method in terms of enucleation rates (Wakayama et al. 1998). However, removal of the whole spindle and a portion of the surrounding cytoplasm together with the chromosomes may reduce the potential of these cytoplasts to later reprogram the transferred somatic nucleus and to support further development of the cloned embryos (Simerly et al. 2003, 2004, Miyara et al. 2006, Van Thuan et al. 2006, 
Costa-Borges et al. 2009). Moreover, ME of mouse oocytes is time consuming and technically demanding, due to the difficulties in distinguishing the meiotic spindle in the cytoplasm of the oocytes. This process can only be successfully performed after a lot of practice (Kishigami et al. 2006a) and with the use of microscopes equipped with modulated contrast Hoffman or Nomarski optics, or more recently the Oosight system (Markoulaki et al. 2008), which are expensive.

In efforts to make oocyte enucleation technically easier and less invasive to the oocytes and to improve the competence of the resultant cytoplasts for SCNT, several approaches and timings for the removal of chromosome have been tested (reviewed in Fulka et al. (2004) and Li et al. (2004)). Among them, chemically assisted (AE) and chemically induced (IE) enucleation protocols could represent alternative models to ME. The AE method, initially developed by Yin et al. (2002) in porcine oocytes, is based on the use of microtubule depolymerizing drugs to induce a cortical protrusion in the membrane of Mll-stage oocytes containing all the chromosomes. This protrusion makes the localization of the chromosomes simple and straightforward, without the need for special optics. In a previous study, we have demonstrated that the AE method can also be successfully applied to mouse oocytes, yielding high rates of protrusion formation ( $84 \%$ ) and high rates of enucleation $(\sim 90 \%)$ after the subsequent removal of the protrusion by micromanipulation. Moreover, AE avoids the removal of spindle microtubules and results in the loss of half the amount of cytoplasm volume than when ME is performed (Costa-Borges et al. 2009). Although healthy cloned animals from different domestic species have been produced using cytoplasts prepared by AE (Yin et al. 2002, 2005, Kawakami et al. 2003, Vajta et al. 2003, Lan et al. 2008), the full-term development of AE cytoplasts after SCNT remains to be demonstrated in the mouse.

IE is another technically easy enucleation procedure that is based on applying the microtubule depolymerizing drugs to pre-activated oocytes to induce the extrusion of all the chromosomes within the second polar body (PB2). The enucleation efficiencies of IE are generally low (20\% in the mouse; Ibáñez et al. 2003), but aspiration of the PB2 with a micropipette can increase the efficiency up to $90 \%$, as it avoids the reintegration of the chromosomes into the cytoplasm in some oocytes that cannot extrude the PB2 completely (Costa-Borges et al. 2011). The cytoplasts prepared according to this method proved to be competent to support embryonic development to term after reconstruction with embryonic cell nuclei, but the embryonic developmental rates were lower than those when ME cytoplasts were used (Gasparrini et al. 2003). Recently, we demonstrated that if NT of the somatic cells is performed prior to the activation and the antimitotic treatment, blastocyst rates can be increased to values similar to those obtained with ME cytoplasts (Costa-Borges et al. 2011). However, the development to term of the resultant embryos was not tested in this study.

In addition to the use of alternative methods of oocyte enucleation, enhancing the potential of the resulting cytoplasts for nuclear reprogramming by treatment with epigenetic modifier drugs may also help to improve the success of the SCNT technique. In this sense, several studies have revealed that the transient treatment of mouse SCNT embryos with a histone deacetylase inhibitor (HDACi) like trichostatin A (TSA) or valproic acid (VPA) can significantly enhance the potential of the clones to develop in vitro and to term (Kishigami et al. 2006b, Rybouchkin et al. 2006, Costa-Borges et al. 2010). These studies have been performed only on cloned embryos produced using ME procedures, but the effects of the HDACis in cytoplasts prepared by $\mathrm{AE}$ or IE have never been explored.

In our study, we investigate the effect of the combination of different enucleation approaches with the use of an HDACi on the success of the SCNT technique. To this aim, we compared the in vitro embryonic development, acetylation status of histone H3 lysine 14 (H3K14), blastocyst quality, ntESCs establishment potential, and embryonic development to term, between VPA-treated mouse cloned embryos generated by $\mathrm{ME}, \mathrm{AE}$, or IE procedures.

\section{Results}

\section{Histone acetylation levels in SCNT embryos produced using $M E, A E$, and IE procedures}

The ratios of the acetylated H3K14 (Ac-H3K14)/DNA signal intensities at different time points after NT in cloned embryos produced using the three enucleation procedures are shown in Table 1. The Ac-H3K14/DNA ratio 10 min after injection of the cumulus cell nucleus into cytoplasts prepared by $\mathrm{ME}$ and $\mathrm{AE}$, or into nonmanipulated oocytes that were next subjected to IE, was between 0.91 and 0.98 and no significant differences were found among the three groups. From this time point, these values significantly decreased in oocytes enucleated by $\mathrm{ME}$ and $\mathrm{AE}$, concomitant with premature chromosome condensation, and by $3 \mathrm{~h}$ after NT, acetylation of $\mathrm{H} 3 \mathrm{~K} 14$ was practically undetectable in both the groups, as evidenced in Fig. 1. By contrast, in the IE group, the Ac-H3K14/DNA ratio showed 50\% decrease $90 \mathrm{~min}$ after nucleus injection, with no chromosome condensation observed, and started increasing again by $3 \mathrm{~h}$ after NT, when acetylation signals were significantly higher than those obtained in the $M E$ and $A E$ groups. Afterward, by $6 \mathrm{~h}$ after NT, the formation of pseudopronuclei in embryos prepared by ME or AE was accompanied by increase in the Ac-H3K14/DNA ratios, which became equivalent to those obtained in embryos prepared from oocytes 
Table 1 Ratios of the Ac-histone H3 lysine 14/DNA signal intensities at different time points after nuclear transfer (NT) in cloned embryos produced using mechanical (ME), assisted (AE), or induced (IE) enucleation procedures.

\begin{tabular}{|c|c|c|c|c|c|}
\hline \multirow[b]{2}{*}{ Group } & \multicolumn{5}{|c|}{ Time points after NT } \\
\hline & $10 \mathrm{~min}$ & $90 \mathrm{~min}$ & $3 \mathrm{~h}$ & $6 \mathrm{~h}$ & $9 \mathrm{~h}$ \\
\hline Cloned $\mathrm{ME}^{\mathrm{a}}$ & $0.91^{*}$ & - & $0.22 *$ & $0.73^{*}$ & $1.04 *$ \\
\hline Cloned $\mathrm{AE}^{\mathrm{a}}$ & $0.98^{*}$ & - & $0.12 *$ & $0.78^{*}$ & $0.91^{*}$ \\
\hline Cloned IE ${ }^{\mathrm{b}}$ & $0.93^{*}$ & 0.53 & $0.68^{\dagger}$ & $0.93^{*}$ & $1.03^{*}$ \\
\hline
\end{tabular}

${ }^{*}+$ Values with different superscripts within the same column differ significantly $(P<0.05)$.

${ }^{a}$ Activation of the reconstructed cytoplasts was performed $3 \mathrm{~h}$ after NT.

${ }^{\mathrm{b}}$ Activation of the reconstructed oocytes was performed $10 \mathrm{~min}$ after NT.

enucleated by IE. By $9 \mathrm{~h}$ after NT, the initial Ac-H3K14/ DNA ratios observed $10 \mathrm{~min}$ after the nucleus injection had been restored in all groups.

\section{In vitro embryonic development of SCNT embryos generated using $M E, A E$, and IE procedures}

The majority of oocytes in the ME group survived the removal of spindle chromosomes complex $(97.4 \%$, Table 2). In the AE protocol, $97.7 \%$ of the oocytes treated with nocodazole (NOC) formed a cortical protrusion and $96.7 \%$ of them survived protrusion aspiration. In the IE group, $90.2 \%$ of the nucleus-injected oocytes showed a partially or completely extruded PB2 after ethanol activation and NOC treatment, and $93.8 \%$ of them survived PB2 aspiration.

In the three groups of reconstructed oocytes, activation rates after $6 \mathrm{~h}$ of incubation in $\mathrm{SrCl}_{2}$, as judged from the presence of one or more pronuclei (only one in the IE oocytes), were similarly high (>92.6\%). The twocell and morula rates of cloned embryos generated from cytoplasts prepared by ME and AE procedures were very similar and significantly higher than those obtained in IE group. The highest rates of blastocyst formation were achieved with cytoplasts prepared by $\mathrm{AE}$, although no differences were found when compared with ME. Blastocyst rates were also equivalent between the IE and the ME groups.

\section{Embryo quality in SCNT blastocysts generated using cytoplasts prepared by $M E, A E$, and IE procedures}

The total and inner cell mass (ICM) mean cell numbers in control parthenogenetically activated and in cloned blastocysts produced by the three enucleation procedures are shown in Table 3. Although the total cell number was significantly higher in parthenogenetic blastocysts when compared with the three groups of cloned embryos, no differences were observed in the mean number of ICM cells among any of the groups.

\section{Establishment of ntESCs from SCNT blastocysts produced using cytoplasts prepared by $M E, A E$, and IE procedures}

ESC lines positive for the three pluripotency markers analyzed could be derived from all groups of control and cloned embryos (Table 4). An example of the ntESC derivation process from an SCNT blastocyst generated from cytoplasts prepared by IE, and pluripotency
$\mathrm{ME}+\mathrm{NT}$
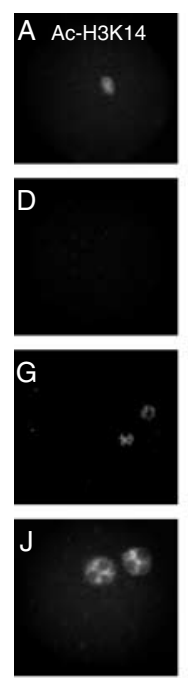
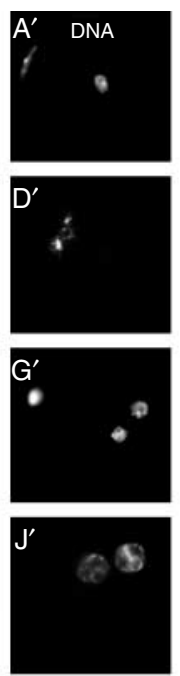

$\mathrm{AE}+\mathrm{NT}$
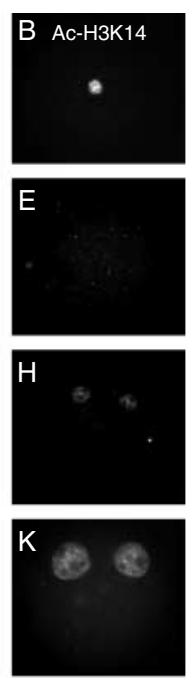
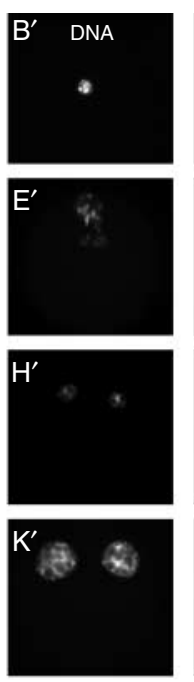

$\mathrm{NT}+\mathrm{IE}$
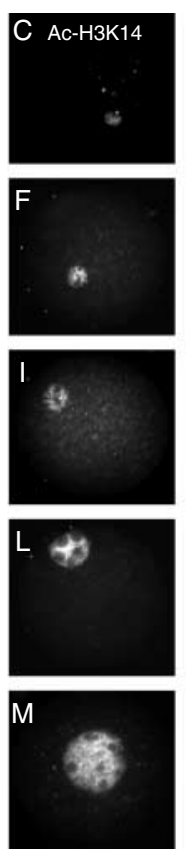
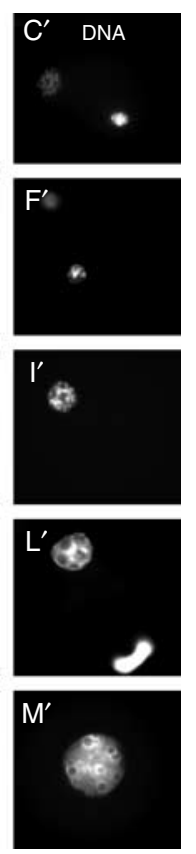

Figure 1 Acetylation level of H3K14 in VPAtreated cloned mouse embryos produced by three different enucleation procedures at different time points after nucleus injection. On the left: SCNT embryos produced from mechanically enucleated (ME) oocytes that were fixed $10 \mathrm{~min}(\mathrm{~A}), 3 \mathrm{~h}(\mathrm{D})$, $6 \mathrm{~h}(\mathrm{G})$, and $9 \mathrm{~h} \mathrm{(J)}$ after NT. In the middle: SCNT embryos generated from cytoplasts prepared by assisted enucleation (AE) that were fixed $10 \mathrm{~min}$ (B), $3 \mathrm{~h}(\mathrm{E}), 6 \mathrm{~h}(\mathrm{H})$, and $9 \mathrm{~h}(\mathrm{~K})$ following NT. On the right: SCNT embryos produced by injection of a cumulus cell nucleus into non-manipulated oocytes, which were then subjected to the induced enucleation (IE) protocol combined with the mechanical aspiration of the PB2. The reconstructed oocytes were fixed $10 \mathrm{~min}$ after nucleus injection (C), 90 min post-activation in ethanol, immediately after PB2 removal (F), and $3 \mathrm{~h}(\mathrm{I}), 6 \mathrm{~h}(\mathrm{~L})$, and $9 \mathrm{~h}(\mathrm{M})$ post-NT. The corresponding DNA staining is shown for all embryos $\left(A^{\prime}-M^{\prime}\right)$. Magnification $\times 400$. 
Table 2 Comparative in vitro development of cloned embryos produced from cytoplasts prepared by mechanical (ME), assisted (AE), or induced (IE) enucleation procedures.

\begin{tabular}{|c|c|c|c|c|c|c|c|c|c|}
\hline \multirow[b]{2}{*}{ Group } & \multirow[b]{2}{*}{$n$} & \multirow{2}{*}{$\begin{array}{l}\text { No. of } \\
\text { oocytes with } \\
\text { protrusion } \\
(\%)\end{array}$} & \multirow{2}{*}{$\begin{array}{c}\text { No. of } \\
\text { oocytes } \\
\text { with PB2 } \\
(\%)\end{array}$} & \multirow{2}{*}{$\begin{array}{l}\text { No. of } \\
\text { enucleated } \\
\text { oocytes }\end{array}$} & \multirow{2}{*}{$\begin{array}{l}\text { No. of recon- } \\
\text { structed } \\
\text { oocytes acti- } \\
\text { vated in } \mathrm{SrCl}_{2}\end{array}$} & \multirow{2}{*}{$\begin{array}{l}\text { No. of recon- } \\
\text { structed } \\
\text { oocytes with } \\
\text { pronuclei }\end{array}$} & \multicolumn{3}{|c|}{ SCNT-embryos with pronuclei developed to $(\%)$} \\
\hline & & & & & & & Two cell & Morula & Blastocyst \\
\hline Cloned ME & 265 & - & - & $258(97.4)^{*}$ & 242 & $224(92.6)^{*}$ & $210(93.8)^{*}$ & $151(67.4)^{*}$ & $73(32.5)^{*,+}$ \\
\hline Cloned AE & 341 & $333(97.7)$ & - & $322(96.7)^{*}$ & 290 & $271(93.4)^{*}$ & $244(90.1)^{*}$ & $175(64.6)^{*}$ & $98(36.3)^{\dagger}$ \\
\hline Cloned IE & 319 & - & $289(90.2)$ & $271(93.8)^{*}$ & 271 & $264(97.4)^{+}$ & $217(82.2)^{\dagger}$ & $117(44.3)^{+}$ & $68(25.3)^{*}$ \\
\hline
\end{tabular}

${ }^{*},{ }^{\dagger}$ Values with different superscripts within the same column differ significantly $(P<0.05)$.

confirmation of the ntESC lines by immunofluorescence, is shown in Fig. 2.

All cloned and control blastocysts used in the ESC derivation process attached to the feeder cell monolayer within the first $24 \mathrm{~h}$. The competence to produce outgrowths after 7 days in culture was significantly decreased in the three groups of cloned embryos when compared with both control fertilized and parthenogenetic embryos, and significant differences were also observed between the ME and the AE cloned groups. In spite of this, efficiencies of ESC lines derivation, ranging from 9.4 to $29.4 \%$, were equivalent among all control and cloned groups.

\section{Full-term development of SCNT embryos produced by $M E, A E$, and IE procedures}

A total of 219 two-cell stage cloned embryos generated from cytoplasts prepared by ME were transferred into the oviducts of 12 surrogate females and, as a result, two cloned pups developed to term and were born alive (Table 5). Full-term development was also obtained, for the first time in the mouse, using cytoplasts prepared by $\mathrm{AE}$ procedures. In this case, from the 205 cloned embryos transferred into 14 females, one stillborn and one cloned pup born alive were obtained. No full-term development resulted from the 232 cloned embryos produced with IE cytoplasts transferred into the oviducts of 13 females. As expected, the highest rates of full-term development were achieved when in vivo fertilized embryos were transferred (28 pups/36 transferred embryos into three females).

All cloned pups that were born alive had body weights equivalent to those of non-cloned pups (Table 5). The placenta weights of the clones obtained with $\mathrm{ME}$ and $\mathrm{AE}$ procedures were very similar, but between two and three times heavier than those of the noncloned pups produced from in vivo fertilized embryos.

\section{Discussion}

Successful development of cloned embryos requires the efficient reprogramming of the donor nucleus in order to silence somatic gene expression and to activate an embryonic pattern of gene expression. Reprogramming events can be measured functionally by evaluating the development of the cloned embryos at different levels, including the rates of blastocyst formation, the proportion of SCNT embryos surviving to term, or the frequencies at which ntESCs can be established (Hochedlinger \& Jaenisch 2006). In addition, as nuclear reprogramming in cloned embryos is thought to occur at an epigenetic level and as one of the epigenetic pathways related to chromatin structure is the global level of histone acetylation (Yang et al. 2007), the acetylation dynamics in core histones after NT can also be used as a good marker of the extent of nuclear reprogramming (Wang et al. 2007). In particular, acetylation of $\mathrm{H} 3 \mathrm{~K} 14$ plays an important role in mediating nucleosome remodeling, facilitating the access of the transcriptional machinery to nucleosomal DNA (MacDonald \& Howe 2009), and its acetylation/ deacetylation dynamics has been analyzed in several studies involving SCNT embryos prepared by ME (Rybouchkin et al. 2006, Wang et al. 2007).

In our study, the acetylation dynamics of H3K14 after SCNT was very similar between ME and AE groups, but different from that observed in cytoplasts prepared by IE. In ME or AE cytoplasts, a rapid and almost complete H3K14 deacetylation occurred in the somatic nucleus during the first $3 \mathrm{~h}$ after injection, followed by an equally rapid and complete re-acetylation after activation. A similar H3K14 acetylation dynamics has been described by others for cloned embryos produced from ME cytoplasts and treated with TSA (Wang et al. 2007). In contrast, in IE cytoplasts, the deacetylation of H3K14

Table 3 Mean total and inner cell mass cell numbers in control parthenogenetically-activated oocytes (PA) and in cloned blastocysts produced from enucleated oocytes prepared by mechanical (ME), assisted (AE), and induced (IE) enucleation procedures.

\begin{tabular}{lccc}
\hline & \multirow{2}{*}{$\begin{array}{c}\text { No. of blasto- } \\
\text { cysts analyzed }\end{array}$} & \multicolumn{2}{c}{ Mean cell number $( \pm$ s.D. $)$} \\
\cline { 3 - 4 } Control PA & 50 & Total & ICM \\
Cloned ME & 35 & $63 \pm 16^{*}$ & $17 \pm 5^{*}$ \\
Cloned AE & 33 & $59 \pm 14^{+}$ & $15 \pm 5^{*}$ \\
Cloned IE & 31 & $67 \pm 12^{+}$ & $16 \pm 4^{*}$ \\
\end{tabular}

${ }^{*}{ }^{\dagger}$ Values with different superscripts within the same column differ significantly $(P<0.05)$. 
Table 4 Establishment of embryonic stem cell (ESC) lines from control in vivo fertilized and parthenogenetically activated (PA) blastocysts and from cloned blastocysts produced from cytoplasts prepared by mechanical (ME), assisted (AE), or induced (IE) enucleation procedures.

\begin{tabular}{lccc}
\hline Group & $\boldsymbol{n}$ & $\begin{array}{c}\text { No. of } \\
\text { outgrowths }(\%)\end{array}$ & $\begin{array}{c}\text { No. of } \\
\text { ESC lines }(\%)\end{array}$ \\
\hline Control fertilized & 25 & $25(100)^{*}$ & $4(16.0)^{*}$ \\
Control PA & 34 & $30(88.2)^{*}$ & $10(29.4)^{*}$ \\
Cloned ME & 43 & $27(62.8)^{\dagger}$ & $5(11.6)^{*}$ \\
Cloned AE & 32 & $12(37.5)^{\ddagger}$ & $3(9.4)^{*}$ \\
Cloned IE & 35 & $17(48.6)^{\dagger, \ddagger}$ & $4(11.4)^{*}$
\end{tabular}

$*^{t+, \neq}$ Values with different superscripts within the same column differ significantly $(P<0.05)$.

occurred at a much lower level and re-acetylation started before a complete deacetylation had been reached. Because no differences were found in terms of Ac-H3K14/DNA patterns between ME (in which the whole spindle is removed) and AE cytoplasts (in which the spindles are depolymerized before enucleation), microtubule-associated materials potentially present in AE cytoplasts but absent from ME cytoplasts do not seem to have an effect in Ac-H3K14/DNA ratios. In this sense, the differences registered in the Ac-H3K14/DNA signals between IE and ME or AE groups cannot be attributed to the potential presence of more or less spindle-associated materials in the cytoplasts produced. Instead, the differences encountered between groups are probably explained by the different times at which the reconstructed oocytes were activated (immediately after NT in the IE group versus $3 \mathrm{~h}$ after NT in the ME and AE groups). Indeed, previous studies have reported that histone acetylation at specific chromatin locations occurs at the time of oocyte activation and/or at early postactivation periods (Kim et al. 2003, Spinaci et al. 2004, Rybouchkin et al. 2006). Alternatively, the two-step activation protocol used in the IE group could also account for the differences observed with the ME and AE groups, in which a single step of $\mathrm{SrCl}_{2}$ activation was applied.
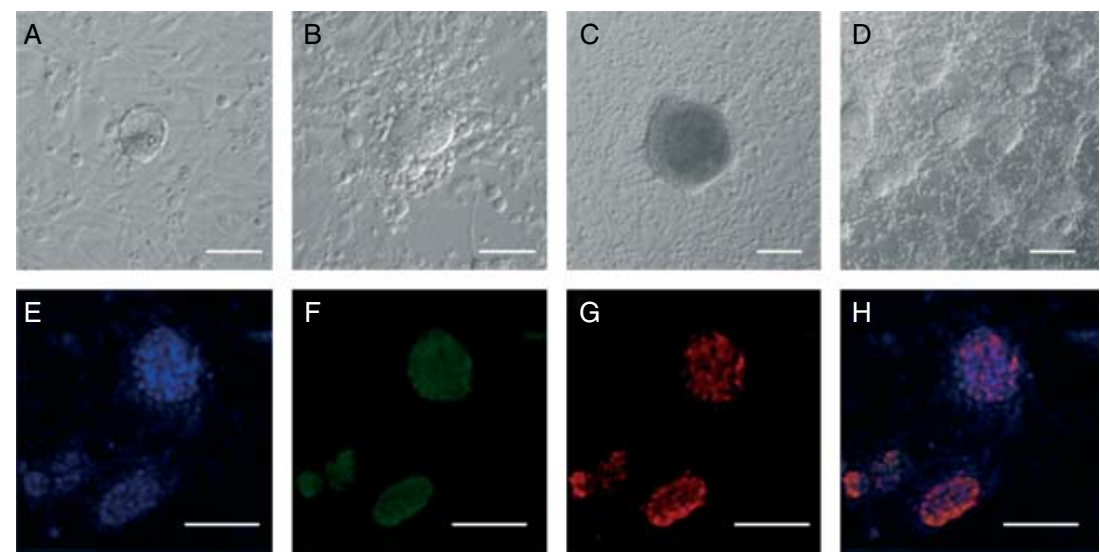

Whether the dynamics of H3K14 acetylation observed in $\mathrm{ME}$ and $\mathrm{AE}$ groups corresponds to a more or less efficient nuclear reprogramming compared with IE cytoplasts, however, is not clear. On the one hand, it has been suggested that hyperacetylation of core histones is correlated with a transcriptional permissive state of the chromatin. This is thought to be necessary for the activation of embryonic genes during nucleus reprogramming and could explain the beneficial effects of applying HDACis treatments before and during activation in cloned embryos produced with $\mathrm{ME}$ procedures to prevent histone deacetylation in the transferred nucleus (Rybouchkin et al. 2006). In this sense, the lower deacetylation activity in the IE cytoplasts could represent an advantage of the IE protocol with regard to $\mathrm{ME}$ or $\mathrm{AE}$ methods concerning nuclear reprogramming. But, on the other hand, studies indicate that a complete deacetylation of the lysine residues of core histones before the beginning of the re-acetylation, as occurred in our ME and $\mathrm{AE}$ cytoplasts, may be necessary for the correct regulation of gene expression and the establishment of totipotency in the cloned embryos (Wang et al. 2007). Histone deacetylation would allow the silencing of the somatic gene expression program before the initiation of the embryonic pattern of gene expression is induced by histone re-acetylation. This acetylation dynamic is probably facilitated by the remodeling of the transferred nucleus, including nuclear envelope breakdown and premature chromosome condensation, which in MII oocytes are promoted by the activities of maturation promoting factor (MPF) and mitogen-activated protein kinases (MAPK; Kono 1997). In our IE protocol, oocytes are activated immediately after NT, resulting in a quick decline in MPF and MAPK levels that could limit the time over which nuclear remodeling occurs and allow the expression of embryonic genes before the somatic gene expression program has been turned off.

Which of the two histone acetylation patterns observed in our study corresponds with a higher reprogramming capacity of the cytoplasts was not
Figure 2 (A-D) Derivation process of an ntESC line from an SCNT blastocyst generated from a cytoplast produced by induced enucleation. (A) SCNT blastocyst attached to the feeder cell monolayer. (B) A 7-day outgrowth. (C) A 20-day ntESC-like colony. (D) ntESC-like line. (E-H) Expression of characteristic pluripotency markers in an ntESC line. (E) Hoechst counterstaining. (F) POU5F1 (Oct4) expression. (G) NANOG expression. $(\mathrm{H})$ Merged image. Scale bars: $100 \mu \mathrm{m}(\mathrm{A}$ and $\mathrm{B})$ and $200 \mu \mathrm{m}(\mathrm{C}-\mathrm{H})$. 
Table 5 Comparative full-term development of control in vivo fertilized embryos and of cloned embryos produced from enucleated oocytes prepared by mechanical (ME), assisted (AE), or induced (IE) enucleation procedures.

\begin{tabular}{|c|c|c|c|c|c|c|}
\hline \multirow[b]{2}{*}{ Group } & \multirow{2}{*}{$\begin{array}{l}\text { No. of two-cell } \\
\text { embryos } \\
\text { transferred }\end{array}$} & \multirow[b]{2}{*}{$\begin{array}{c}\text { No. of live } \\
\text { offspring (\%) }\end{array}$} & \multirow[b]{2}{*}{$\begin{array}{l}\text { No. of dead } \\
\text { fetuses }(\%)\end{array}$} & \multicolumn{2}{|c|}{ Average weight (mg) } & \multirow[b]{2}{*}{$\begin{array}{c}\text { No. of placenta } \\
\text { only }(\%)\end{array}$} \\
\hline & & & & $\begin{array}{c}\text { Body } \\
\text { (mean } \pm \text { s.D.) }\end{array}$ & $\begin{array}{c}\text { Placenta } \\
\text { (mean } \pm \text { s.D.) }\end{array}$ & \\
\hline Control fertilized & 36 & $28(77.8)^{*}$ & 0 & $1523.6 \pm 101.3^{*}$ & $102.1 \pm 26.9^{*}$ & 0 \\
\hline Cloned ME & 219 & $2(0.9)^{\dagger}$ & 0 & $1494.5 \pm 180.8^{*}$ & $287.9 \pm 69.1^{\dagger}$ & $1(0.5)$ \\
\hline Cloned AE & 205 & $1(0.5)^{\dagger}$ & $1(0.5)^{\mathrm{a}}$ & $16 \overline{52} .7$ & $22 \overline{6} .7$ & $1(0.5)$ \\
\hline Cloned IE & 232 & 0 & 0 & - & - & 0 \\
\hline
\end{tabular}

${ }^{*}, \mathrm{t}$ Values with different superscripts within the same column and category differ significantly between treatments $(P<0.05)$.

${ }^{a} 641.8 \mathrm{mg}$ fetus body weight/466.7 mg placenta.

reflected in the in vitro development rates of the cloned embryos or in the quality of the blastocysts produced. Thus, although the rates of development to the two-cell and morula stages were lower in the IE group, the final frequencies of blastocyst formation were equivalent to those obtained in the ME group, indicating a similar reprogramming capacity between the two types of cytoplasts. These results are in accordance to our previous findings, showing that injection of the donor nucleus into IE cytoplasts prior to the activation and the antimitotic treatment results in similar blastocyst rates than when using ME procedures (Costa-Borges et al. 2011). Furthermore, results of this study also show that the quality of the SCNT blastocysts produced, in terms of total and ICM mean cell numbers, is not affected by the enucleation method applied.

Differences in $\mathrm{H} 3 \mathrm{~K} 14$ acetylation dynamics were neither translated to the efficiencies of ntESC derivation from the three groups of blastocysts. Outgrowth formation was less efficient in cloned embryos than in control fertilized or parthenogenetically activated blastocysts and, because parthenogenetic blastocysts showed a higher total mean number of cells than all groups of cloned blastocysts, these differences could be explained by their higher proliferation capacity. Nevertheless, production of ESC lines after extensive culture of the outgrowths was similarly efficient in all groups of embryos, and all ntESC and control ESC lines displayed an equivalent morphology of the colonies and an equivalent pattern of expression of pluripotency markers.

In the mouse, it is well known that the efficiency of SCNT procedures (Wakayama et al. 2005, Kishigami et al. 2007) and of ESC derivation (Kawase et al. 1994, Suzuki et al. 1999) is influenced by the genetic background. The observed efficiencies of ESC derivation from our control embryos are similar to those previously reported by Gong et al. (2008) in the hybrid B6CBAF1 strain, which was $15.3 \%$ for parthenogenetic blastocysts. Owing to the infrequent use of hybrid B6CBAF1 animals in SCNT experiments (Gasparrini et al. 2003, Maalouf et al. 2009, Costa-Borges et al. 2010), no ntESC lines have been derived from this genetic background until now, but the efficiencies obtained in ntESC derivation in this study are similar to those reported for other hybrid strains (Wakayama et al. 2005).

To our knowledge, ntESC lines have never been derived from cloned blastocysts produced using $\mathrm{AE}$ and IE procedures. As for cloned ME embryos, recent studies have shown that the use of HDACis increases the potential of cloned blastocysts to produce ntESCs lines (Kishigami et al. 2006b, Ono et al. 2010), by increasing the proliferation rate during the outgrowth phase in the derivation process (Dai et al. 2010). Moreover, we have previously demonstrated the beneficial effects of the VPA treatments on the quality of the SCNT blastocysts produced, which showed $30-35 \%$ increase in total and ICM cell numbers in comparison to non-treated SCNT embryos (Costa-Borges et al. 2010). In line with these previous studies, it is, therefore, not surprising that VPAtreated cloned blastocysts derived from ME procedures in this study show the same potential as control fertilized and parthenogenetic embryos to produce ESC lines. And, according to our results, this potential would not be affected by the enucleation protocol used to produce the cloned embryos.

Compared with preimplantation development and ntESC derivation, development to term is much more constrained by genetic and epigenetic abnormalities of the embryos. As a result, the potential of cloned embryos to develop into live pups is much lower than to develop into blastocysts or to produce ntESC lines (Yang et al. 2007). Successful production of live offspring is uncommon in mice and it is actually considered as the definite revelation of the perfect nuclear reprogramming (Hochedlinger \& Jaenisch 2006). For this reason, in this study, we also wanted to determine the potential of the SCNT embryos produced to develop to term after transferring them into surrogate females. Because in a previous study, we were unable to achieve full-term development from B6CBAF1 cloned embryos prepared by ME unless they were treated with the HDACis TSA or VPA (Costa-Borges et al. 2010), and in this study, we decided to include VPA in all our SCNT protocols to increase the chances of obtaining cloned mice. For the first time, a cloned mouse was successfully obtained 
from cloned embryos prepared by AE. Healthy cloned animals from different species, including pigs, cows, cats, and goats, have previously been produced by others using $\mathrm{AE}$ procedures, with efficiencies equivalent to those obtained using mechanically enucleated oocytes (Yin et al. 2002, 2005, Tani et al. 2006, Lan et al. 2008). Similarly, in our study, the cloning efficiency using AE cytoplasts was equivalent to that of ME cytoplasts, demonstrating that AE cytoplasts are competent to fully reprogram the transferred nucleus in the presence of VPA and, therefore, that the AE procedure can be used as an alternative method to $\mathrm{ME}$ to enucleate mouse oocytes. The production of cloned mice from both $\mathrm{ME}$ and $\mathrm{AE}$ cytoplasts also support our previous findings on the beneficial effects of VPA treatments for mouse cloning in the B6CBAF1 strain (Costa-Borges et al. 2010). These beneficial effects, corroborated in miniature pig SCNT embryos (Miyoshi et al. 2010), have recently been questioned by Ono et al (2010), who compared the effects of different HDACis on cloning BD129F1 mice. The discrepancy of results in the mouse species can be probably attributed to strain-specific differences, as not all HDACis are equally effective in all genetic backgrounds (Kishigami et al. 2007, Van Thuan et al. 2009).

With regard to the IE procedure, although Gasparrini et al. (2003) previously reported the production of a cloned mouse using cytoplasts prepared by IE, we were unable to obtain live offspring from the IE group. It should be mentioned, however, that they used ESCs as karyoplast donors, which are known to be easier to reprogram than the cumulus cells used in our study (Hochedlinger \& Jaenisch 2006). Even though a much higher number of embryos should be transferred to reach a conclusion, due to the low cloning efficiency in general with the mouse strain used in this study, the lack of offspring from cloned embryos produced from IE cytoplasts apparently indicates a reduced reprogramming capacity of IE cytoplasts when compared with that of ME or AE cytoplasts. And, according to the particular H3K14 acetylation dynamics of the donor nucleus observed in this group of cloned embryos, this could suggest that histone deacetylation may be required before activation-induced re-acetylation, to achieve a correct pattern of gene expression in the cloned embryo that allows full-term development. Because nuclear reprogramming is a slow and progressive process and because events that occur early after nucleus injection may be essential prerequisites for later events (Latham 2005), the extent of nuclear reprogramming achieved in cloned IE embryos could have been sufficient for the dedifferentiation of the somatic nucleus to a totipotent embryonic state, but insufficient for the redifferentiation to different somatic cell types during post-implantation development (Yang et al. 2007). This would explain the similar rates of blastocyst development and ntESC derivation between IE and $\mathrm{AE}$ or ME cloned embryos, and the lack of full-term development in the IE group.
In this scenario, it is possible that delaying activation after NT during the IE procedure would allow a higher level of histone deacetylation to occur in the donor nucleus and therefore improve the reprogramming capacity of the IE cytoplasts. Analysis of pluripotency markers expression, such as POU5F1 (Oct4), as well as of acetylation levels of histone lysines other than H3K14 in IE embryos also deserves further investigation.

In summary, this study demonstrates the potential of cytoplasts prepared either by $\mathrm{AE}$ or IE procedures to reprogram somatic nuclei and generate cloned blastocysts of good quality, which have a similar potential to establish ntESCs lines to those prepared by ME. However, only AE cytoplasts seem to possess the same reprogramming ability as ME cytoplasts to achieve fullterm development of the cloned embryos. The production of a cloned mouse from VPA-treated SCNT embryos produced using $\mathrm{AE}$ procedures demonstrates that the use of microtubule depolymerizing drugs, like $\mathrm{NOC}$, is compatible with the application of HDACi treatments, which are currently being used to enhance reprogramming of the somatic nucleus in most cloning protocols. Our study may open the doors to research groups willing to perform SCNT studies in mouse or other mammalian species where chromosome localization is difficult. In these cases, AE can facilitate oocyte enucleation without the need for expensive microscope optics, or for potentially damaging Hoechst staining and u.v. irradiation, as it is normally required in $\mathrm{ME}$ procedures.

\section{Materials and Methods}

Unless indicated, all reagents were purchased from Sigma.

\begin{abstract}
Animals
All experiments were conducted according to the guidelines for animal care and handling approved by the Ethics Committee on Animal and Human Research of the Universitat Autònoma de Barcelona. Hybrid B6CBAF1 (C57BL/6J XCBA/J) female mice (age 6-12 weeks) were used as oocyte and somatic cell (cumulus cell) donors and for the collection of the in vivo fertilized embryos that were used as controls in ESCs establishment and embryo transfer procedures. Outbred CD1 females (age 6-12 weeks) mated with normal or vasectomized males of the same strain were used as foster or surrogate mothers respectively.
\end{abstract}

\section{Collection of oocytes and embryos}

Females were superovulated by i.p. injection of $5 \mathrm{IU}$ of pregnant mare's serum gonadotrophin (Intervet, Barcelona, Spain) followed $48 \mathrm{~h}$ later by $5 \mathrm{IU}$ of human chorionic gonadotrophin (hCG; Farma-Lepori, Barcelona, Spain). Cumulusoocyte complexes were collected from the oviducts 13-14 h after hCG administration in Hepes-buffered CZB medium 
(H-CZB, Chatot et al. 1989) and treated with hyaluronidase $(300 \mathrm{U} / \mathrm{ml})$ in $\mathrm{H}-\mathrm{CZB}$ at $37^{\circ} \mathrm{C}$ until cumulus cells dispersed. Cumulus-free oocytes were then washed and kept in KSOM culture medium (106-D; Millipore, Madrid, Spain) under oil, at $37^{\circ} \mathrm{C}$ with $5 \% \mathrm{CO}_{2}$ in air, until use. For obtention of in vivo fertilized pronuclear-stage embryos, superovulated females were mated with B6CBAF1 males after hCG administration. Embryos were then collected from the oviducts 20-22 h later, treated with hyaluronidase, and cultured in $\mathrm{KSOM}$ at $37^{\circ} \mathrm{C}$ and $5 \% \mathrm{CO}_{2}$ until the two-cell or blastocyst stages.

\section{Preparation of donor cells for NT}

Cumulus cells were removed from the oocytes using hyaluronidase, as described earlier, and washed by centrifugation ( $5 \mathrm{~min}$ at $300 \mathrm{~g}$ ) in $\mathrm{H}-\mathrm{CZB}$. The cumulus cell pellet was then re-suspended in a small volume of $3 \%(\mathrm{v} / \mathrm{v})$ polyvinyl pyrrolidone in $\mathrm{H}-\mathrm{CZB}$ and kept on ice until the moment of the nuclear injection.

\section{Oocyte enucleation and NT}

All micromanipulations were performed with an Eppendorf micromanipulation system installed on an Olympus IX71 microscope, using Piezo-driven pipettes. A schematic view of the different methods used to produce the cloned embryos by $\mathrm{ME}, \mathrm{AE}$, or IE procedures is shown in Fig. 3. In cytoplasts prepared by $\mathrm{ME}$ or $\mathrm{AE}$, enucleation was performed before NT. In the ME group, oocytes were pre-treated for 5 min with $5 \mu \mathrm{g} / \mathrm{ml}$ cytochalasin $\mathrm{B}(\mathrm{CB})$ in $\mathrm{H}-\mathrm{CZB}$ medium and then enucleated by aspiration of the spindle-chromosomes complex with a enucleation pipette (outer diameter 8-9 $\mu \mathrm{m}$ ), as described previously (Wakayama et al. 1998). In AE experiments, oocytes were first treated, in groups of $15-20$, in $0.3 \mu \mathrm{g} / \mathrm{ml} \mathrm{NOC} \mathrm{diluted}$ in $\mathrm{KSOM}$ for $30 \mathrm{~min}$ at $37^{\circ} \mathrm{C}$ with $5 \% \mathrm{CO}_{2}$. After the antimitotic treatment, oocytes were washed in one drop of $\mathrm{H}-\mathrm{CZB}$ and immediately transferred to the micromanipulation dish for aspiration of the cortical protrusion in $\mathrm{H}-\mathrm{CZB}-\mathrm{CB}$ medium, as described previously (Costa-Borges et al. 2009). Enucleated oocytes prepared either by ME or AE procedures were then washed extensively and returned to the incubator in KSOM medium for $1-2 \mathrm{~h}$ before reconstruction. Somatic nuclei were then isolated from cumulus cells by gently pipetting the cells in and out of the injection pipette (outer diameter 6-7 $\mu \mathrm{m}$ ) and were immediately transferred into the cytoplasts. Afterward, the reconstructed oocytes were cultured for $2-3 \mathrm{~h}$ in KSOM supplemented with 2 mM VPA and then were activated for $6 \mathrm{~h}$ in $\mathrm{Ca}^{2+}$-free $\mathrm{CZB}$ medium supplemented with $10 \mathrm{mM}$ $\mathrm{SrCl}_{2}$ and $5 \mu \mathrm{g} / \mathrm{ml} \mathrm{CB}$, in the continuous presence of VPA (Costa-Borges et al. 2010). In the IE group, a reverse-order SCNT protocol was used, in which NT was performed before enucleation as previously reported (Wakayama et al. 2003, Costa-Borges et al. 2011). Non-manipulated MII oocytes were first individually injected with a donor nucleus. After NT, the reconstructed oocytes were pre-activated by a $5 \mathrm{~min}$ exposure to freshly prepared $7 \%(\mathrm{v} / \mathrm{v})$ ethanol at $37^{\circ} \mathrm{C}$ and treated for $15 \mathrm{~min}$ in $0.3 \mu \mathrm{g} / \mathrm{ml} \mathrm{NOC}$ diluted in $\mathrm{KSOM}$ medium. Then, they were washed and cultured in KSOM medium supplemented with $2 \mathrm{mM}$ VPA until PB2 extrusion. At between
90 and 120 min post-activation (p.a.) with ethanol, oocytes showing a partially or completely extruded PB2 were transferred to drops of $\mathrm{H}-\mathrm{CZB}-\mathrm{CB}$ for mechanical aspiration of the PB2 with an enucleation pipette. Once enucleated, the reconstructed oocytes were subjected to a second activation in $\mathrm{Ca}^{2+}$-free $\mathrm{CZB}$ with $10 \mathrm{mM} \mathrm{SrCl} 2,5 \mu \mathrm{g} / \mathrm{ml} \mathrm{CB}$ and $2 \mathrm{mM}$ VPA for $6 \mathrm{~h}$ at $37^{\circ} \mathrm{C}$ and $5 \% \mathrm{CO}_{2}$. Finally, the reconstructed oocytes were moved to KSOM drops for another $2 \mathrm{~h}$ of treatment with VPA.

Irrespective of the protocol used, cloned embryos showing visible pronuclei at the end of the treatments were considered to be activated and were extensively washed and cultured in KSOM medium until the two-cell or blastocyst stages.

\section{Immunofluorescence analysis of histone acetylation levels in SCNT embryos}

SCNT embryos were fixed at room temperature in $4 \%(\mathrm{w} / \mathrm{v})$ paraformaldehyde in $\mathrm{H}-\mathrm{CZB}$ medium at different time points after nucleus injection (10 min, $90 \mathrm{~min}, 3 \mathrm{~h}, 6 \mathrm{~h}$, and $9 \mathrm{~h}$ ). Once fixed, they were permeabilized in PBS containing $0.5 \%$ $(\mathrm{v} / \mathrm{v})$ Triton X-100, 3\% (v/v) goat serum, and $0.2 \%(\mathrm{w} / \mathrm{v})$ sodium azide. The samples were then washed and stored at $4{ }^{\circ} \mathrm{C}$ in a PBS blocking solution (Wickramasinghe \& Albertini 1992). When all samples had been collected, they were simultaneously processed for immunofluorescence analysis, so that staining conditions were identical for all groups. Embryos were first incubated for $1 \mathrm{~h}$ in a 1:500 dilution of a rabbit polyclonal anti-acetyl-H3K14 primary antibody (06-911, Millipore), washed four times in blocking solution for $10 \mathrm{~min}$ each, and then incubated for $1 \mathrm{~h}$ with Alexa Fluor 594 goat anti-rabbit IgG $(6 \mu \mathrm{g} / \mathrm{ml}$; Molecular Probes, Barcelona, Spain). After several washes, the samples were stained with $10 \mu \mathrm{g} / \mathrm{ml}$ Hoechst 33258 (Molecular Probes) for $10 \mathrm{~min}$ and mounted on slides in $50 \%(\mathrm{v} / \mathrm{v})$ glycerol/PBS containing $25 \mathrm{mg} / \mathrm{ml}$ of sodium azide. Samples were examined using an epifluorescence microscope (Bx60, Olympus, Spain) equipped with specific filters for Hoechst and Texas Red and a $50 \mathrm{~W}$ mercury lamp. Digital images of the Ac-H3K14 and DNA signals were acquired on Genus Software (Olympus) using the same contrast, brightness, and exposure settings for all embryos. The mean values of the fluorescence intensities were measured on the Ac-H3K14 and DNA channels with Image J Software $(\mathrm{NIH}$, Bethesda, MD, USA) by selecting all the area of the pronuclei in 10-20 SCNT embryos for each time point and enucleation group. The average profiles represented as the ratio of Ac-H3K14/DNA signals were then used for the comparison between the different groups.

\section{Blastocyst differential staining}

A simplified technique, previously described by Thouas et al. (2001), was used for the differential staining and counting of ICM and trophectoderm (TE) cells in cloned blastocysts. Blastocysts obtained by parthenogenetic activation of nonmanipulated MII oocytes were used as controls to have a strict control of the time when developmental process was initiated. Briefly, embryos that reached the blastocyst stage $96 \mathrm{~h}$ p.a. were first incubated in $\mathrm{H}-\mathrm{CZB}$ medium with $1 \%(\mathrm{v} / \mathrm{v})$ Triton 


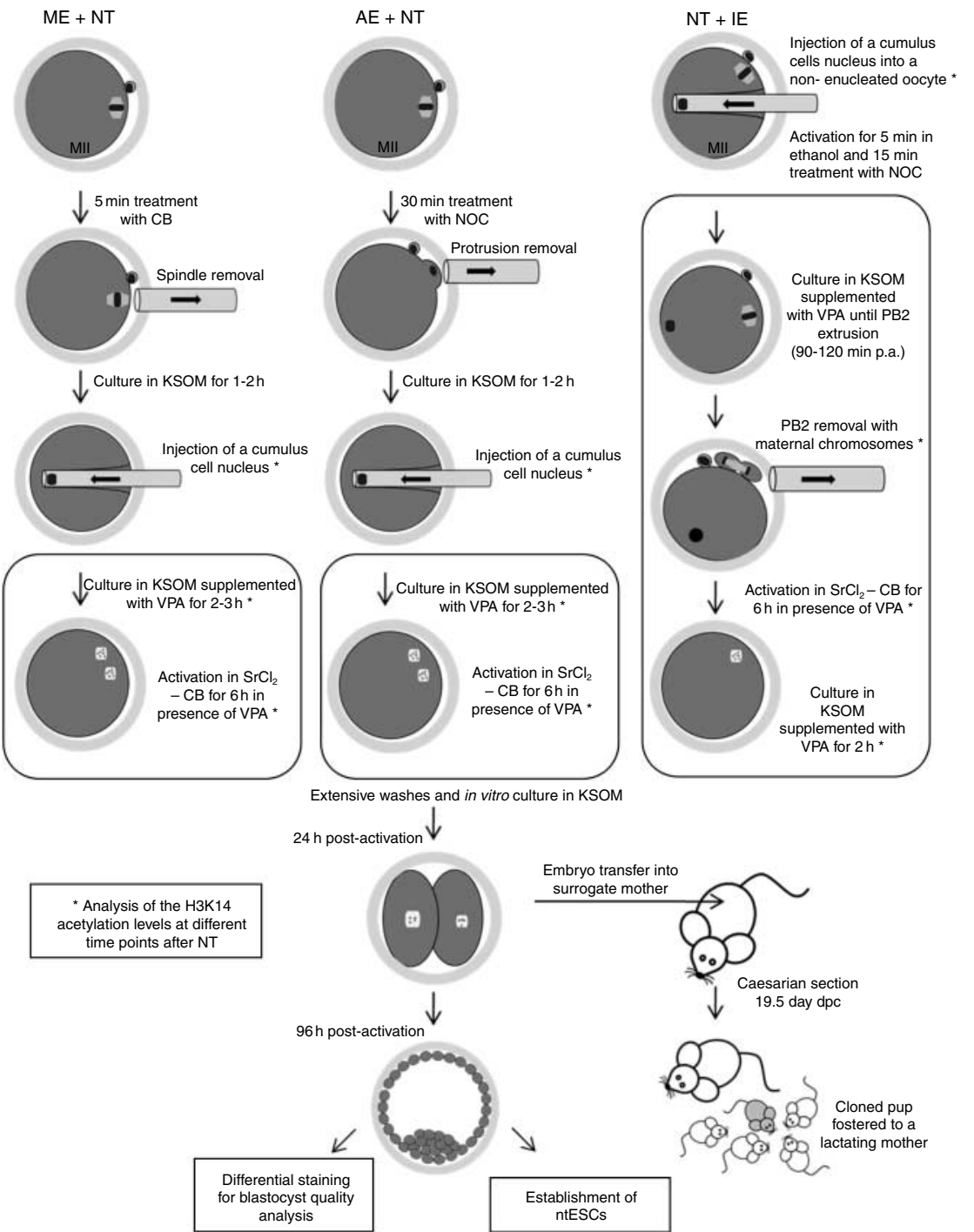

Figure 3 Schematic view of the experiments performed. Boxed areas indicate the period of VPA exposure in each protocol. See text for details.
$\mathrm{X}-100$ and $100 \mu \mathrm{g} / \mathrm{ml}$ propidium iodide for up to $10-12 \mathrm{~s}$. Blastocysts were then immediately transferred into a fixative solution of $100 \%$ ethanol supplemented with $25 \mu \mathrm{g} / \mathrm{ml}$ Hoechst 33258 and stored in this solution at $4{ }^{\circ} \mathrm{C}$ overnight. The next day, blastocysts were washed and mounted on a glass microscope slide in a $3 \mu \mathrm{l}$ drop of glycerol and flattened with a coverslip. Cell counting was performed from digital images obtained on an inverted microscope (IX71, Olympus) fitted with an ultraviolet lamp and an excitation filter that allows the visualization of the red and blue fluorochromes simultaneously (U-MNV, Olympus).

\section{Establishment of ESC lines}

ntESC lines were derived from the three groups of SCNT embryos at the blastocyst stage, following the protocol described by Wakayama et al. (2007). As control groups, in vivo fertilized and parthenogenetic B6CBAF1 embryos at the blastocyst stage were used. Briefly, blastocysts were treated with a solution of Tyrode's acid to digest the zona pellucida and seeded onto a feeder cell monolayer of mouse embryonic fibroblasts (ECACC, Salisbury, UK) inactivated with mitomycin C (Invitrogen) (Martin \& Evans 1975). The culture medium used was a defined ESC establishment DMEM (Invitrogen) supplemented with $100 \mu \mathrm{M}$ 2- $\beta$-mercaptoethanol (Invitrogen), $200 \mathrm{mM}$ L-glutamine (Invitrogen), 100X non-essential amino acids (Invitrogen), $10^{3}$ units/ml leukemia inhibitory factor (Millipore), 20\% (v/v) knockout serum replacement (Invitrogen), and $0.1 \mathrm{mg} / \mathrm{ml} \mathrm{ACTH}$. Embryos were kept in culture until outgrowths were observed $\sim 7$ days after seeding. Outgrowths of embryonic cells were mechanically disaggregated by a trypsin-EDTA (LabClinics, Barcelona, Spain) treatment, using a mouth-controlled Pasteur pipette to draw the clump in and out of the end of the pipette in order to reduce the ESC-like clump into smaller cell fragments and a few single cells (Robertson 1987). Passaging was performed approximately seven times until ESC lines were considered to be definitively established. Culture was done at $37{ }^{\circ} \mathrm{C}$ in a $5 \% \mathrm{CO}_{2}$ atmosphere and the ntESC establishment medium was changed every 2 days. 


\section{Characterization of ESC lines}

ESC lines were first characterized based on the morphology of their colonies. In this sense, lines with colonies that presented rounded cells and defined limits without the presence of differentiated cells were classified as ESC-like lines. Afterward, pluripotency of the selected ESC-like lines was assessed by immunofluorescence analysis of specific markers of undifferentiated cells, such as NANOG, POU5F1, and SOX2. First, ESC colonies were fixed in 4\% paraformaldehyde during $15 \mathrm{~min}$, washed three times in a PBS solution, and permeabilized in a PBS solution containing $0.5 \%(\mathrm{v} / \mathrm{v})$, Triton X-100, 3\% (v/v) goat serum, and $0.2 \%(\mathrm{v} / \mathrm{v})$ sodium azide during $30 \mathrm{~min}$. Next, colonies were incubated overnight at $4{ }^{\circ} \mathrm{C}$ in primary antibodies, washed three times in PBS solution, and incubated with the corresponding secondary antibody during $2 \mathrm{~h}$ at room temperature. Primary antibodies used were rabbit polyclonal anti-NANOG (1:200, ab21603, Abcam), mouse monoclonal anti-POU5F1 (1:50, sc-5279 Santa Cruz, Heidelberg, Germany), and rabbit polyclonal anti-SOX2 (1:200, AB5603, Millipore). Secondary antibodies, used at $6 \mu \mathrm{g} / \mathrm{ml}$, were Alexa Fluor 594 goat anti-rabbit IgG and Alexa Fluor 488 chicken anti-mouse IgG (Molecular Probes). Finally, samples were stained with Hoechst 33258 at $10 \mu \mathrm{g} / \mathrm{ml}$ for $10 \mathrm{~min}$ as a nuclear counterstain. Mounted samples were examined with an epifluorescence microscope (Bx41, Olympus) and digital images were acquired on Isis Software version 5.3.3 (MetaSystems, Barcelona, Spain).

\section{Embryo transfer}

CD-1 females mated with vasectomized males of the same strain were used as recipients. All embryos were transferred at the two-cell stage into the oviducts of 0.5 day post-coitum (dpc) recipients. Between 9 and 32 SCNT embryos were cotransferred with one to three parthenogenetic embryos (10-15\% of the total of embryos transferred; Meng et al. 2008) to each female. As a control of the embryo transfer procedure, in vivo fertilized embryos were also transferred to other CD-1 recipients. Females were killed at $19.5 \mathrm{dpc}$ and pups were delivered by caesarean section. The pups and their corresponding placentas were weighted in an analytic scale and the cloned pups were fostered to a lactating CD-1 mother.

\section{Statistical analysis}

At least three replicates of each experiment were performed on separate days and the results obtained were pooled. Data were analyzed by $\chi^{2}$ test or Fisher's exact test to compare embryonic development and ESCs establishment between the different groups. Data on mean number of cells in blastocysts, Ac-H3K14 fluorescence intensity ratios, and body and placenta weights were analyzed by one-way ANOVA and compared by Tukey-Kramer test. A probability value of $P<0.05$ was considered to be statistically significant.

\section{Experimental design}

To evaluate and compare the potential of the cytoplasts prepared by $M E, A E$, and IE procedures for genomic reprogramming and embryonic development, cloned embryos treated with VPA were produced as summarized in Fig. 3. In a first series of experiments, some SCNT embryos were fixed at different time points after cumulus cell nucleus injection (10 min, $90 \mathrm{~min}, 3 \mathrm{~h}, 6 \mathrm{~h}$, and $9 \mathrm{~h}$ ) and processed for immunofluorescence detection of Ac-H3K14. The remaining SCNT embryos were cultured in vitro and their embryonic development assessed until the blastocyst stage. By 96 h p.a., cloned blastocysts obtained from the three enucleation procedures and parthenogenetic blastocysts, used as a control, were processed for differential staining and counting of ICM and TE cells or used for the establishment of ESCs. As a control of the ESCs derivation process, in vivo fertilized embryos collected at pronuclear stage and cultured in vitro up to the blastocyst were also included.

In a second series of experiments, aimed to determine the full-term developmental potential of the SCNT embryos produced, the embryos were cultured in vitro for $24 \mathrm{~h}$ and those that reached the two-cell stage were transferred into the oviducts of $0.5 \mathrm{dpc}$ pseudopregnant females. The pups were delivered by caesarean section at $19.5 \mathrm{dpc}$ and fostered to a lactating mother (Fig. 3).

\section{Declaration of interest}

The authors declare that there is no conflict of interest that could be perceived as prejudicing the impartiality of the research reported.

\section{Funding}

This study was supported by the Universitat Autònoma de Barcelona (EME 2004-24), the Spanish Ministerio de Educación y Ciencia (BIO 2006-11792), and the Generalitat de Catalunya (2009SGR-00282). N Costa-Borges is a fellow of the Portuguese Fundação para a Ciência e Tecnologia and S Gonzalez is a fellow of the Spanish Ministerio de Educación y Ciencia.

\section{Acknowledgements}

We thank Jonatan Lucas for technical assistance and all staff from the Servei $d^{\prime}$ Estabulari for housing the mice.

\section{References}

Chatot CL, Ziomek CA, Bavister BD, Lewis JL \& Torres I 1989 An improved culture medium supports development of random-bred 1-cell mouse embryos in vitro. Journal of Reproduction and Fertility 86 679-688. (doi:10.1530/jrf.0.0860679)

Costa-Borges N, Paramio MT, Calderón G, Santaló J \& Ibáñez E 2009 Antimitotic treatments for chemically assisted oocyte enucleation in nuclear transfer procedures. Cloning Stem Cells 11 153-166. (doi:10. 1089/clo.2008.0031)

Costa-Borges N, Santaló J \& Ibáñez E 2010 Comparison between the effects of valproic acid and trichostatin $A$ on the in vitro development, blastocyst quality, and full-term development of mouse somatic cell nuclear transfer embryos. Cellular Reprogramming 12 437-446. (doi:10.1089/cell.2009. 0108)

Costa-Borges N, Paramio MT, Santaló J \& Ibáñez E 2011 Demecolcine- and nocodazole-induced enucleation in mouse and goat oocytes for the 
preparation of recipient cytoplasts in somatic cell nuclear transfer procedures. Theriogenology 75 527-541. (doi:10.1016/j.theriogenology. 2010.09.022)

Cowan CA, Atienza J, Melton DA \& Eggan K 2005 Nuclear reprogramming of somatic cells after fusion with human embryonic stem cells. Science 309 1369-1373. (doi:10.1126/science.1116447)

Dai X, Hao J, Hou XJ, Hai T, Fan Y, Yu Y, Jouneau A, Wang L \& Zhou Q 2010 Somatic nucleus reprogramming is significantly improved by $\mathrm{m}$-carboxycinnamic acid bishydroxamide, a histone deacetylase inhibitor. Journal of Biological Chemistry 285 31002-31010. (doi:10.1074/jbc. M110.136085)

Fulka J Jr, Loi P, Fulka H, Ptak G \& Nagai T 2004 Nucleus transfer in mammals: noninvasive approaches for the preparation of cytoplasts. Trends in Biotechnology 22 279-283. (doi:10.1016/j.tibtech.2004.04. 002)

Gasparrini B, Gao S, Ainslie A, Fletcher J, McGarry M, Ritchie WA, Springbett AJ, Overström EW, Wilmut I \& De Sousa PA 2003 Cloned mice derived from embryonic stem cell karyoplasts and activated cytoplasts prepared by induced enucleation. Biology of Reproduction 68 1259-1266. (doi:10.1095/biolreprod.102.008730)

Gong SP, Lee EJ, Lee ST, Kim H, Lee SH, Han HJ \& Lim JM 2008 Improved establishment of autologous stem cells derived from preantral follicle culture and oocyte parthenogenesis. Stem Cells and Development 17 695-712. (doi:10.1089/scd.2007.0168)

Hochedlinger K \& Jaenisch R 2006 Nuclear reprogramming and pluripotency. Nature 441 1061-1067. (doi:10.1038/nature04955)

Ibáñez E, Albertini DF \& Overström EW 2003 Demecolcine-induced oocyte enucleation for somatic cell cloning: coordination between cell cycle egress, kinetics of cortical cytoskeletal interactions, and second polar body extrusion. Biology of Reproduction 68 1249-1258. (doi:10. 1095/biolreprod.102.008292)

Kawakami M, Tani T, Yabuuchi A, Kobayashi T, Murakami H, Fujimura T, Kato Y \& Tsunoda Y 2003 Effect of demecolcine and nocodazole on the efficiency of chemically assisted removal of chromosomes and the developmental potential of nuclear transferred porcine oocytes. Cloning Stem Cells 5 379-387. (doi:10.1089/153623003772032871)

Kawase E, Suemori H, Takahashi N, Okazaki K, Hashimoto K \& Nakatsuji N 1994 Strain difference in establishment of mouse embryonic stem (ES) cell lines. International Journal of Developmental Biology 38 385-390.

Kim JM, Liu H, Tazaki M, Nagata M \& Aoki F 2003 Changes in histone acetylation during mouse oocyte meiosis. Journal of Cell Biology 162 37-46. (doi:10.1083/jcb.200303047)

Kishigami S, Wakayama S, Thuan NV, Ohta H, Mizutani E, Hikichi T, Bui HT, Balbach S, Ogura A, Boiani M et al. 2006a Production of cloned mice by somatic cell nuclear transfer. Nature Protocols 1 125-138. (doi:10.1038/nprot.2006.21)

Kishigami S, Mizutani E, Ohta H, Hikichi T, Thuan NV, Wakayama S, Bui HT \& Wakayama T 2006b Significant improvement of mouse cloning technique by treatment with trichostatin A after somatic nuclear transfer. Biochemical and Biophysical Research Communications 34 183-189. (doi:10.1016/j.bbrc.2005.11.164)

Kishigami S, Bui HT, Wakayama S, Tokunaga K, Van Thuan N, Hikichi T, Mizutani E, Ohta H, Suetsugu R, Sata T et al. 2007 Successful mouse cloning of an outbred strain by trichostatin A treatment after somatic nuclear transfer. Journal of Reproduction and Development 53 165-170. (doi:10.1262/jrd.18098)

Kono T 1997 Nuclear transfer and reprogramming. Reviews of Reproduction 2 74-80. (doi:10.1530/ror.0.0020074)

Lan GC, Wu YG, Han D, Ge L, Liu Y, Wang HL, Wang JZ \& Tan JH 2008 Demecolcine-assisted enucleation of goat oocytes: protocol optimization, mechanism investigation, and application to improve the developmental potential of cloned embryos. Cloning Stem Cells 10 189-202. (doi:10.1089/clo.2007.0088)

Latham KE 2005 Early and delayed aspects of nuclear reprogramming during cloning. Biology of the Cell 97 119-132. (doi:10.1042/ BC20040068)

Li GP, White KL \& Bunch TD 2004 Review of enucleation methods and procedures used in animal cloning: state of the art. Cloning Stem Cells 6 5-13. (doi:10.1089/15362300460743781)

Maalouf WE, Liu Z, Brochard V, Renard JP, Debey P, Beaujean N \& Zink D 2009 Trichostatin A treatment of cloned mouse embryos improves constitutive heterochromatin remodeling as well as developmental potential to term. BMC Developmental Biology 9 11. (doi:10.1186/ 1471-213X-9-11)

MacDonald VE \& Howe LJ 2009 Histone acetylation: where to go and how to get there. Epigenetics 4 139-143. (doi:10.4161/epi.4.3.8484)

Markoulaki S, Meissner A \& Jaenisch R 2008 Somatic cell nuclear transfer and derivation of embryonic stem cells in the mouse. Methods $\mathbf{4 5}$ 101-114. (doi:10.1016/j.ymeth.2008.04.002)

Martin GR \& Evans MJ 1975 Differentiation of clonal lines of teratocarcinoma cells: formation of embryoid bodies in vitro. PNAS 72 1441-1445. (doi:10.1073/pnas.72.4.1441)

Meng Q, Wang M, Stanca CA, Bodo S \& Dinnyes A 2008 Cotransfer of parthenogenetic embryos improves the pregnancy and implantation of nuclear transfer embryos in mouse. Cloning Stem Cells 10 429-434. (doi:10.1089/clo.2008.0003)

Miyara F, Han Z, Gao S, Vassena R \& Latham KE 2006 Non-equivalence of embryonic and somatic cell nuclei affecting spindle composition in clones. Developmental Biology 289 206-217. (doi:10.1016/j.ydbio. 2005.10.030)

Miyoshi K, Mori H, Mizobe Y, Akasaka E, Ozawa A, Yoshida M \& Sato M 2010 Valproic acid enhances in vitro development and Oct-3/4 expression of miniature pig somatic cell nuclear transfer embryos. Cellular Reprogramming 12 67-74. (doi:10.1089/cell.2009.0032)

Ogonuki N, Inoue K, Yamamoto Y, Noguchi Y, Tanemura K, Suzuki O, Nakayama H, Doi K, Ohtomo Y, Satoh M et al. 2002 Early death of mice cloned from somatic cells. Nature Genetics 30 253-254. (doi:10.1038/ ng841)

Okita K, Hong H, Takahashi K \& Yamanaka S 2010 Generation of mouseinduced pluripotent stem cells with plasmid vectors. Nature Protocols $\mathbf{5}$ 418-428. (doi:10.1038/nprot.2009.231)

Ono T, Li C, Mizutani E, Terashita Y, Yamagata K \& Wakayama T 2010 Inhibition of class Ilb histone deacetylase significantly improves cloning efficiency in mice. Biology of Reproduction 83 929-937. (doi:10.1095/ biolreprod.110.085282)

Robertson EJ 1987 Embryo-derived stem cell lines. In Teratocarcinomas and Embryonic Stem Cells. A Practical Approach, pp 71-112. Washington DC: IRL Press.

Rybouchkin A, Kato Y \& Tsunoda Y 2006 Role of histone acetylation in reprogramming of somatic nuclei following nuclear transfer. Biology of Reproduction 74 1083-1089. (doi:10.1095/biolreprod. 105.047456)

Simerly C, Dominko T, Navara C, Payne C, Capuano S, Gosman G, Chong KY, Takahashi D, Chace C, Compton D et al. 2003 Molecular correlates of primate nuclear transfer failures. Science 300 297. (doi:10. 1126/science.1082091)

Simerly C, Navara C, Hyun SH, Lee BC, Kang SK, Capuano S, Gosman G, Dominko T, Chong KY, Compton D et al. 2004 Embryogenesis and blastocyst development after somatic cell nuclear transfer in nonhuman primates: overcoming defects caused by meiotic spindle extraction. Developmental Biology 276 237-252. (doi:10.1016/j.ydbio. 2004.10.006)

Spinaci M, Seren E \& Mattioli M 2004 Maternal chromatin remodeling during maturation and after fertilization in mouse oocytes. Molecular Reproduction and Development 69 215-221. (doi:10.1002/mrd.20117)

Suzuki O, Matsuda J, Takano K, Yamamoto Y, Asano T, Naiki M \& Kusanagi M 1999 Effect of genetic background on establishment of mouse embryonic stem cells. Experimental animals/Japanese Association for Laboratory Animal Science 48 213-216.

Takahashi K \& Yamanaka S 2006 Induction of pluripotent stem cells from mouse embryonic and adult fibroblast cultures by defined factors. Cell 126 663-676. (doi:10.1016/j.cell.2006.07.024)

Tamashiro KL, Wakayama T, Blanchard RJ, Blanchard DC \& Yanagimachi R 2000 Postnatal growth and behavioral development of mice cloned from adult cumulus cells. Biology of Reproduction 63 328-334. (doi:10.1095/ biolreprod63.1.328)

Tamashiro KL, Wakayama T, Akutsu H, Yamazaki Y, Lachey JL, Wortman MD, Seeley RJ, D'Alessio DA, Woods SC, Yanagimachi R et al. 2002 Cloned mice have an obese phenotype not transmitted to their offspring. Nature Medicine 8 262-267. (doi:10.1038/nm0302-262)

Tanaka S, Oda M, Toyoshima Y, Wakayama T, Tanaka M, Yoshida N, Hattori N, Ohgane J, Yanagimachi R \& Shiota K 2001 Placentomegaly in 
cloned mouse concepti caused by expansion of the spongiotrophoblast layer. Biology of Reproduction 65 1813-1821. (doi:10.1095/biolreprod65.6.1813)

Tani T, Shimada H, Kato Y \& Tsunoda Y 2006 Demecolcine-assisted enucleation for bovine cloning. Cloning Stem Cells 8 61-66. (doi:10. 1089/clo.2006.8.61)

Thouas GA, Korfiatis NA, French AJ, Jones GM \& Trounson AO 2001 Simplified technique for differential staining of inner cell mass and trophectoderm cells of mouse and bovine blastocysts. Reproductive Biomedicine Online 3 25-29. (doi:10.1016/S1472-6483(10)61960-8)

Thuan NV, Kishigami S \& Wakayama T 2010 How to improve the success rate of mouse cloning technology. Journal of Reproduction and Development 56 20-30. (doi:10.1262/jrd.09-221A)

Vajta G, Lewis IM, Trounson AO, Purup S, Maddox-Hyttel P, Schmidt M, Pedersen HG, Greve T \& Callesen H 2003 Handmade somatic cell cloning in cattle: analysis of factors contributing to high efficiency in vitro. Biology of Reproduction 68 571-578. (doi:10.1095/biolreprod. 102.008771)

Van Thuan N, Wakayama S, Kishigami S \& Wakayama T 2006 Donor centrosome regulation of initial spindle formation in mouse somatic cell nuclear transfer: roles of gamma-tubulin and nuclear mitotic apparatus protein 1. Biology of Reproduction 74 777-787. (doi:10.1095/biolreprod.105.044677)

Van Thuan N, Bui HT, Kim JH, Hikichi T, Wakayama S, Kishigami S, Mizutani E \& Wakayama T 2009 The histone deacetylase inhibitor scriptaid enhances nascent mRNA production and rescues full-term development in cloned inbred mice. Reproduction 138 309-317. (doi:10.1530/REP-08-0299)

Wakayama T \& Yanagimachi R 1999 Cloning of male mice from adult tail-tip cells. Nature Genetics 22 127-128. (doi:10.1038/9632)

Wakayama T, Perry AC, Zuccotti M, Johnson KR \& Yanagimachi R 1998 Full-term development of mice from enucleated oocytes injected with cumulus cell nuclei. Nature 394 369-374. (doi:10.1038/28615)

Wakayama S, Cibelli JB \& Wakayama T 2003 Effect of timing of the removal of oocyte chromosomes before or after injection of somatic nucleus on development of NT embryos. Cloning Stem Cells 5 181-189. (doi:10. 1089/153623003769645848)
Wakayama S, Ohta H, Kishigami S, Thuan NV, Hikichi T, Mizutani E, Miyake M \& Wakayama T 2005 Establishment of male and female nuclear transfer embryonic stem cell lines from different mouse strains and tissues. Biology of Reproduction 72 932-936. (doi:10.1095/ biolreprod.104.035105)

Wakayama S, Hikichi T, Suetsugu R, Sakaide Y, Bui HT, Mizutani E \& Wakayama T 2007 Efficient establishment of mouse embryonic stem cell lines from single blastomeres and polar bodies. Stem Cells 25 986-993. (doi:10.1634/stemcells.2006-0615)

Wang F, Kou Z, Zhang Y \& Gao S 2007 Dynamic reprogramming of histone acetylation and methylation in the first cell cycle of cloned mouse embryos. Biology of Reproduction 77 1007-1016. (doi:10.1095/ biolreprod.107.063149)

Wickramasinghe D \& Albertini DF 1992 Centrosome phosphorylation and the developmental expression of meiotic competence in mouse oocytes. Developmental Biology 152 62-74. (doi:10.1016/0012-1606 (92)90156-B)

Yang X, Smith SL, Tian XC, Lewin HA, Renard JP \& Wakayama T 2007 Nuclear reprogramming of cloned embryos and its implications for therapeutic cloning. Nature Genetics 39 295-302. (doi:10.1038/ ng1973)

Yin XJ, Tani T, Yonemura I, Kawakami M, Miyamoto K, Hasegawa R, Kato Y \& Tsunoda Y 2002 Production of cloned pigs from adult somatic cells by chemically assisted removal of maternal chromosomes. Biology of Reproduction 67 442-446. (doi:10.1095/biolreprod67.2.442)

Yin XJ, Lee HS, Lee YH, Seo YI, Jeon SJ, Choi EG, Cho SJ, Cho SG, Min W, Kang SK et al. 2005 Cats cloned from fetal and adult somatic cells by nuclear transfer. Reproduction 129 245-249. (doi:10.1530/ rep.1.00403)

Received 9 November 2010

First decision 3 December 2010

Revised manuscript received 24 January 2011

Accepted 28 March 2011 